\title{
LAVAPIÉS DIXIT: APUNTES PARA CREJVISITAR LA RECUPERACIÓN DE LOS CENTROS HISTÓRICOS Y SU VIVIENDA
}

\author{
LAVAPIÉS DIXIT: NOTES FOR VISITING THE REVITALIZATION OF HISTORICAL DOWNTOWNS AND \\ THEIR HOUSING
}

\section{MIGLEL ÁNGEL DELGADD² JDSÉ CARLDS HAYAKAWA CASAS³}

Fecha de recepción: I6 de setiembre de 2014

Fecha de aprobación: 20 de noviembre de 2014.

\section{RESUMEN}

Es una idea generalizada pensar que el patrimonio cultural constituye un espectro esencial y dinámico de la actividad humana. Si los centros históricos representan comunidades privilegiadas tanto cuantitativa como cualitativamente de estos conjuntos, es posible entender que la adecuada gestión de dicho patrimonio puede devenir en incremento de la calidad de vida de dichas comunidades. Él análisis de casos de gestión del patrimonio cultural experimentados en centros históricos europeos como Madrid (España) aporta a desarrollar una visión panorámica y a sistematizar las "lecciones aprendidas".

\section{PALABRAS CLAVE}

Ciudad, Centros Históricos, patrimonio cultural, gestión, políticas públicas, Madrid.

\section{ABSTRACT}

It is a common idea thinks that the cultural heritage includes an essential and dynamic menu of human activity. If the historical centers means privileged communities in quantity and quality dimensions, if it is possible understand that the right management of this cultural heritage can become an increase of quality of life of these communities. The analysis of cultural heritage management's cases experienced in European historical centers as Madrid (Spain) which developed experiences about it helps to develop a panoramical view and to organize this data in a systematic way of "learned lessons".

\section{KEYWORDS}

City, Historical Centers, cultural heritage, management, public policies, Madrid.

\footnotetext{
1. El documento presentado refiere al binomio patrimonio y ciudad, que forma parte de la investigación sobre la gestión del patrimonio cultural y los centros históricos que los autores vienen desarrollando. Asimismo, la temática se desarrolla a partir de las ideas principales del texto Ser o no ser infravivienda en Madrid. El caso Lavapiés (diciembre 2008) de autoría del arquitecto Delgado y su labor en la Entidad Gestora de Rehabilitación del Centro Histórico de Madrid-Barrio de Lavapiés, además de la investigación desarrollada allí por el arquitecto Hayakawa en el marco del Programa Formativo en Conservación del Patrimonio Arquitectónico y Urbano de la Fundación Carolina de España.

2. Arquitecto, magíster en Conservación del Patrimonio Edificado de la Universidad Politécnica de Madrid. Su actividad laboral, dedicada a la elaboración y ejecución de proyectos edificatorios en general, la ha ejercido en buena parte como arquitecto en intervenciones de conservación de patrimonio y de restauración y rehabilitación de edificios, tanto en la redacción de proyectos técnicos y dirección de obras como en la gestión de actuaciones. (maditura@arquired.es).

3. Arquitecto, magíster en Arquitectura con mención en Renovación Urbana de la Universidad Nacional de Ingeniería - UNI. Investigador y docente de la UNI en pregrado y en sus maestrías en Regeneración Urbana y de Conservación del Patrimonio Edificado; en la Maestría en Gestión Cultural, Patrimonio y Turismo de la Universidad San Martín de Porres. Es miembro de la Junta Directiva del Comité Nacional del Icomos y del Grupo de Estudios de la Inmigración Japonesa al Perú S. XVII-XX del Instituto Riva Agüero de la Pontificia Universidad Católica del Perú. (josehayakawa@gmail.com).
} 


\section{Introducción}

Reflexionar sobre los decursos de la relación patrimonio y centros históricos, ya sea en Lima, México D.F., Madrid, Estrasburgo, o Tokio debe conducirnos en primer lugar a establecer ciertos consensos conceptuales los cuales aportarán al desarrollo de preguntas e hipótesis de trabajo. En ese marco, brindaremos algunos apuntes sobre las especificidades de "lo patrimonial" -en el marco de una cultura gestionaria- $y$, en ese marco, de los procesos de puesta en valor social de los centros históricos a partir de la casuística elegida. Ello permitirá vislumbrar con mayor claridad algunos de los retos "asumibles" en relación a los centros históricos, a la gestión de su patrimonio cultural y su agenda urbana contemporánea.

\section{Apuntes teóricos para (re)visitar los centros his- tóricos desde la gestión de su patrimonio cul- tural}

El valor es entendido en sus diferentes acepciones como el "Grado de utilidad o aptitud de las cosas, para satisfacer las necesidades o proporcionar bienestar o deleite [...] Alcance de la significación o importancia de una cosa, acción, palabra o frase" (Real Academia Española, 2001, p. 1540). Esta definición ofrece también algunas dimensiones sustanciales del concepto: magnitud de la importancia y generación de bienestar. A ellas, habría que agregarle la vinculación con el "bien", por lo cual el valor se configura en una cualidad por la que resultan estimables. Este tipo de estimación puede ser de diferente índole o magnitud según variables de análisis diversas. Precisamente, resulta de gran importancia caer en cuenta sobre esta situación, ya que cuando nos referimos al patrimonio lo hacemos en relación al bien y por lo tanto al valor como

[...] aprecio hacia determinados objetos por el mérito que atesoran, por la utilidad que manifiestan, o por su aptitud para satisfacer necesidades o proporcionar bienestar. Por todo eso el valor no es siempre inherente a las cosas[...] Se trata. de un concepto relativo sometido a los vaivenes de la percepción y del comportamiento humanos y, por lo tanto, dependiente de un marco de referencias intelectuales, históricas, culturales y psicológicas que varía con las personas y los grupos que atribuyen valor (Ballart, 2002, pp.61-62).

Dicha aproximación, a pesar de incidir restrictivamente en su carácter material con la mención de "cosas" -excluyendo a los bienes no materiales-, cubre satisfactoriamente su multidimensionalidad: estimación, origen asignativo, relatividad, que refiere a una colectividad o individuo. Vinculado al patrimonio, el valor es clasificable en 3 tipos:

a) Un valor de uso [...] en el sentido de pura utilidad, es decir, que sirve para hacer con él[...] que satisface una necesidad material o de conocimiento o un deseo. Es la dimensión utilitaria...

b) Un valor formal [...] responde al hecho de que determinados objetos son apreciados por la atracción que despiertan a los sentidos, por el placer que proporcionan, por razón de la forma y por otras cualidades sensibles, y por el mérito que presentan.

c) Un valor simbólico-significativo [...] la consideración en que se tienen los objetos del pasado en tanto presencias sustitutivas y hacen de nexo entre personas separadas por el tiempo, por lo que son testimonio de ideas, hechos y situaciones del pasado[...] (Ballart, 2002, pp.65-66 ).

Con relación al concepto de patrimonio se ha aproximado una definición muy pertinente y a la vez esencial: "[...]patrimonio viene del latín; es aquello que proviene de los padres. Según el diccionario, patrimonio son los bienes que poseemos, o los bienes que hemos heredado de nuestros ascendientes. Lógicamente patrimonio es también todo lo que traspasamos en herencia" (Ballart y Juan-Tresserras, 2001, p.11). Se deduce una referencia a los "bienes"; es decir, entidades que poseen valor para alguien y que son trasmitidas por herencia, afirmándose con dicho patrimonio el recuerdo y con éste la transmisión de una propiedad común, tanto material como inmaterial. Dicha noción de patrimonio posee como marco la lectura de una lógica conceptual constituida como relación establecida entre "[...]la historia continuada ligada a las actitudes creativas en cada secuencia histórica[...] Configurando nuestro legado actual como conjunción de actuaciones realizadas en el tiempo... pero que nos conducen inevitablemente a la realidad actual [...]" (Riobóo, 2002, p. 9).

Al hablar de patrimonio, debemos caer en cuenta de que su esencia se soporta en tres características esenciales: la temporalidad, la significación y la relatividad.

[...] Todo patrimonio se encuentra acotado en el espacio y en el tiempo. En ese sentido se podría hablar de distintos patrimonios [...] el patrimonio no es inmutable, varía con el tiempo [...] Todo patrimonio es un conjunto muy variado de elementos heredados... Pero puede no existir la conciencia por parte de los herederos de la importancia [...] En tal caso, el patrimonio puede [...] transformarse [...] sin que nadie se dé cuenta... Pero el mismo concepto 
de significación, como implica valores y por tanto mundos de vida diferentes, es un concepto relativo en sí mismo. Depende de los puntos de vista de los diferentes actores involucrados [...] (Lescano y Stolovich, 2000, p.4).

Asimismo, es posible referir la concepción de patrimonio en relación a dos cualidades: construcción social e invención. El primero se relaciona a procesos de legitimación de "universos simbólicos", la cual se soporta indefectiblemente sobre la intervención directa de una hegemonía cultural y social y el segundo a la manipulación, pero no solo de elementos, sino de composiciones: "la invención de la realidad se refiere..., a estos procesos de descontextualización y recontextualización [...]" (Prats, 1997, p. 20). Es por ello que no se puede obviar la comprensión del patrimonio como construcción social.

[...]un artificio, ideado por alguien (o en el decurso de algún proceso colectivo), en algún lugar y momento, para unos determinados fines, e implica, finalmente, que es o puede ser históricamente cambiante, de acuerdo con nuevos criterios o intereses que determinen nuevos fines en nuevas circunstancias. (Prats, 1997, p.20)

$\mathrm{Al}$ adquirir un carácter social, participativo y dinámico, como repertorio de significados continuamente interpretados por una comunidad.

Así, Fernando Carrión sintetiza y refuerza esta lectura dinámica y multiactoral de lo patrimonial conceptualizándolo desde una doble perspectiva:

Es el ámbito de un conflicto social, de la misma manera como ocurre al interior de cualquier núcleo familiar respecto de la herencia. Esto define los sujetos patrimoniales en sus respectivas tensiones e interrelaciones.

Es la lógica de la transferencia socio-generacional del valor patrimonial, en la perspectiva del devenir. Esto es, define el carácter de sustentabilidad o la continuidad del cambio (Carrión, 2000, pp.11-12).

Es también indispensable precisar el sentido del término cultura. Tomo en consideración tres acepciones básicas. La primera la define como "[...]la producción de fenómenos que contribuyen, mediante la presentación o reelaboración simbólica de las estructuras materiales, a comprender, reproducir o transformar el sistema social, es decir, todas las prácticas e instituciones dedicadas a la administración, renovación y reestructuración del sentido" (Cornejo, 1987, p.3). La segunda definición se aproxima a la cultura como "[...] el conjunto de los modos de expresión, de pensamiento y de acción propios de una comunidad dada. Comprende las creencias, las instituciones, las técnicas que imponen un mismo estilo de vida a los miembros de la sociedad a la que asegura la unidad y la estabilidad aunque sufriendo las transformaciones de esta sociedad, transformaciones a las cuales, por otra parte, ella no cesa de contribuir" (Cornejo, 1987, p.3). Por ello, es posible hablar del carácter pluricultural o multicultural de la sociedad peruana. Finalmente, el tercer sentido refiere la particular "[...] opción de cada ser humano en cuanto a la producción o a la experiencia de lo cultural" (Cornejo, 1987, p.4). En ese sentido, hay una asociación con el derecho a la cultura, entendido como el derecho de cada quien a producir libremente con sus propias expresiones culturales y a participar en la vida cultural de la propia comunidad y del mundo.

De otro lado, la conceptualización del centro histórico, enclave latinoamericana, alcanzó una formulación más madura en el Coloquio sobre Preservación de los Centros Históricos ante el Crecimiento de las Ciudades Contemporáneas, en el cual se los identifica como: "[...]todos aquellos asentamientos humanos vivos, fuertemente condicionados por una estructura física proveniente del pasado, reconocibles como representativos de la evolución de un pueblo" (Instituto Nacional de Cultura, 1977, p.19). Un aporte muy interesante y bastante más reciente es su comprensión como:

[...] una relación social compleja y particular donde los sujetos patrimoniales definen el ámbito específico de la conflictividad (la heredad) y el mecanismo de transferencia generacional (sustentabilidad). El traspaso social del testimonio se desarrolla en el marco de un conflicto que debe incrementar valor en el proceso de transmisión (Carrión, 2000, p.12).

En coherencia con esta lectura, la posibilidad de mantener al centro histórico como un "asentamiento humano vivo" radica en la adición de valor que se haga; es decir, añadir más historia o "más pasado al presente". En este marco, es posible definir la gestión del patrimonio cultural como el "[...]conjunto de actuaciones programadas con el objetivo de conseguir una óptima conservación de los bienes patrimoniales y un uso de estos bienes adecuado a las exigencias sociales contemporáneas" (Ballart y Juan-Tresserras, 2001, p.15).

Dicha gestión posee un conjunto de actuaciones destinadas a hacer efectivo el conocimiento, conserva- 
ción y difusión del patrimonio, los cuales se agrupan en tres áreas: planificación, difusión y control.

Entre algunas razones que explican el renovado interés por las centralidades urbanas e históricas son identificables tres procesos:

El deterioro y desvalorización de las áreas centrales-históricas durante largos periodos resulta incompatible con la búsqueda de la sustentabilidad del desarrollo urbano. Así, su despoblamiento sostenido implica "[...]sub-utilización de la infraestructura y de los equipamientos ahí acumulados a lo largo del proceso de urbanización, mientras el financiamiento público de la expansión espacial de las ciudades es cada vez menos sostenible" (Coulomb, 2008: 30). La planeación territorial exige actualmente la necesidad de re-urbanizar, re-funcionalizar, o reciclar las estructuras urbanas pre-existentes.

El "retorno a la ciudad construida" resulta también impulsado por la creciente toma de conciencia, aunque aun insuficientemente difundida en nuestras sociedades, del valor que el patrimonio cultural representa para la memoria y la(s) identidad(es) colectiva(s) de los colectivos sociales, ya sea un barrio, una ciudad o un Estado-nación. Este repotenciado interés por los centros históricos se produce simultáneamente a la profundización del proceso de globalización de los intercambios comerciales y culturales, el cual en su versión más generalizada tiende a homogeneizar los patrones de consumo y a cuestionar la diversidad cultural de "lo local", en favor de "lo global".

Nuestras sociedades urbanas, en especial las grandes áreas metropolitanas, se encuentran en pleno proceso de quedarse la función socioespacial que "hace ciudad": la centralidad. Así, es observable que la mayoría de los llamados nuevos centros o nuevas plazas son como ellos mismos -orgullosamente- refieren "comerciales": “[...]centralidades homogéneas y excluyentes construidas sobre la base de la privatización (segurizante) de los espacios públicos abiertos" (Coulomb, 2008: 30). Así, la crisis de la centralidad urbana resulta el producto final de lo(s) proceso(s) de segregación urbana y de polarización socio-espacial, que viene caracterizando el proceso de urbanización de los últimos tiempos.

En el contexto que inscribe a los centros históricos en los procesos de urbanización y en los cambios demográficos, la globalización y la revolución científico-tecnológica de las comunicaciones, se genera la consolidación de un incierto patrón urbanizador "[...]caracterizado por su desarrollo cualitativo y endógeno - [...] regreso a la ciudad construida- que supera al cuantitativo, exógeno y periférico [...] la centralidad histórica adquiere una nueva cualidad y función que [...], queda pendiente saber cuál es[...]" (Rincón, 2000, p. 121). Ello nos lleva a reflexionar que la manifestación más importante de la cultura desarrollada en la historia de la humanidad -la ciudad y entre ellas el centro histórico- debe asimilar y replantearse como "nuevo proyecto", escenario por la diversidad y el reconocimiento del "otro" y donde deberemos aprender -y aprehender- a "vivir juntos", lo que nos deriva a un concepto que reconstruye el sentido de producir cultura en la ciudad y qué entendemos como "urbanidad" como refiere José López: "Lo que se pretende es facilitar y promover el encuentro enriquecedor de lo diverso, e incluso disfrutar de él, entenderlo como fuente de gozo y de dinamismo de la personalidad y de la vida urbana, para que florezcan la libertad, la igualdad, la fraternidad y el bienestar [...] pero también el reconocimiento y el gozo de lo diverso, las diferentes nociones de vida buena, la relación lectiva con las propias tradiciones y la solidaridad" (López, 2003, p. 28).

\section{Experiencias de recuperación de centros his- tóricos en Europa. 1998-2006: tras los rastros de Lavapiés}

\subsection{Intervención en el ARI sector I de lavapiés. In- troducción histórica}

El barrio de Lavapiés nació como un asentamiento extramuros de la ciudad de Madrid, hasta que el crecimiento de ésta lo incluyó dentro del nuevo cerco perimétrico de la ciudad construido en el siglo XVII. La cartografía del momento mostraba que el trazado de las calles y alineaciones del barrio eran ya prácticamente las mismas que las actuales (Teixeira, 1656, p.1) (Figura 1).

El tipo edificatorio a mediados del siglo XVII se caracteriza por "[...] edificaciones de baja altura, 1 o 2 plantas conformando la manzana quedando el interior como espacio libre privado. Son parcelas de poca fachada, estrechas y profundas, correspondiendo a la típica división de huertas. Las calles son estrechas y con grandes pendientes" (Ruiz, 2006, p.1).

La migración del campo a la ciudad en el siglo XVIII aumenta la densidad poblacional y los edificios incrementan su altura hasta los cuatro pisos; aparecen también las primeras casas de "corrala". La transfor- 


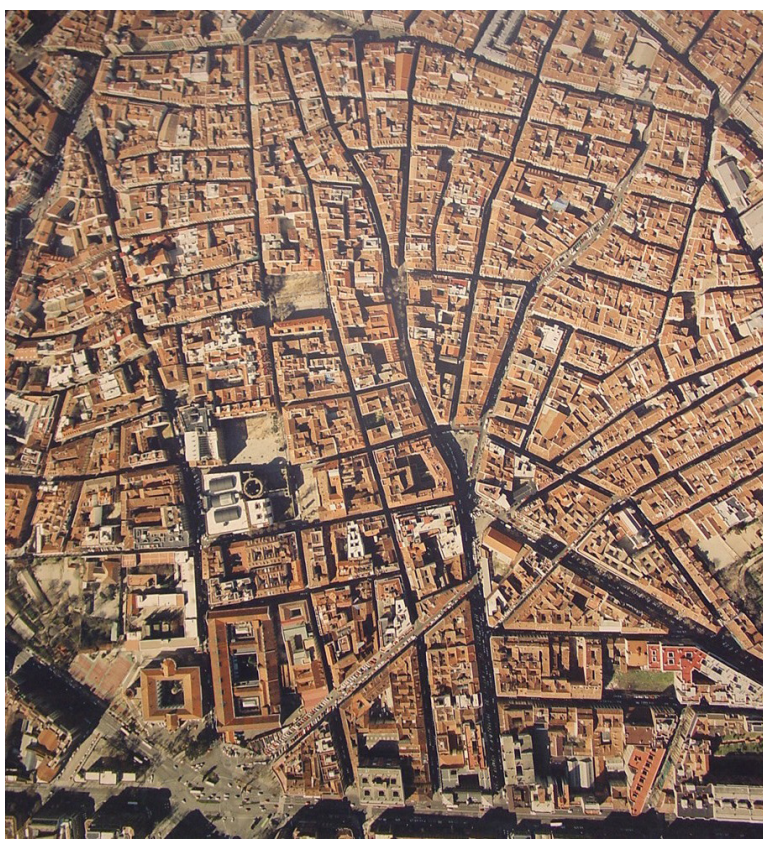

mación en los edificios responde a las siguientes características: "[...]los cuerpos exteriores en algunos casos han incrementado su altura y la huerta trasera se maciza en parte, dejando un patio central desde donde se accede mediante escaleras independientes a los corredores en donde se sitúan las viviendas interiores, de inferior calidad, con una o dos piezas a lo sumo" (Ruiz, 2006, p.1). A la vez, se erigen en este momento varias construcciones destacables, de patrocinio institucional, de mayores dimensiones y calidad. (Figura 2)

Con el avance de la industrialización, a partir de mediados del siglo XIX, hay un incremento poblacional de la ciudad que afectará a este barrio, con una intensa saturación de los espacios interiores de las manzanas, proceso ya iniciado en el siglo anterior con un aumento significativo en el número de plantas. Se consolida el esquema de edificaciones entre medianerías en las manzanas existentes, con pequeños patios de insuficiente ventilación e iluminación natural. Surgen algunos edificios relevantes de tipo fabril. Se demuelen muchos edificios y se los sustituye por otros nuevos, con fachadas más ornamentadas y plantas en general ordenadas simétricamente. Pero no se mejora significativamente la calidad constructiva ni las condiciones de habitabilidad ofrecidas. La morfología y las dimensiones del parcelario continúan siendo similares, con edificaciones construidas sobre parcelas de fachada estrecha y mucha profundidad. (Figura 3) La utilización del edificio con co-

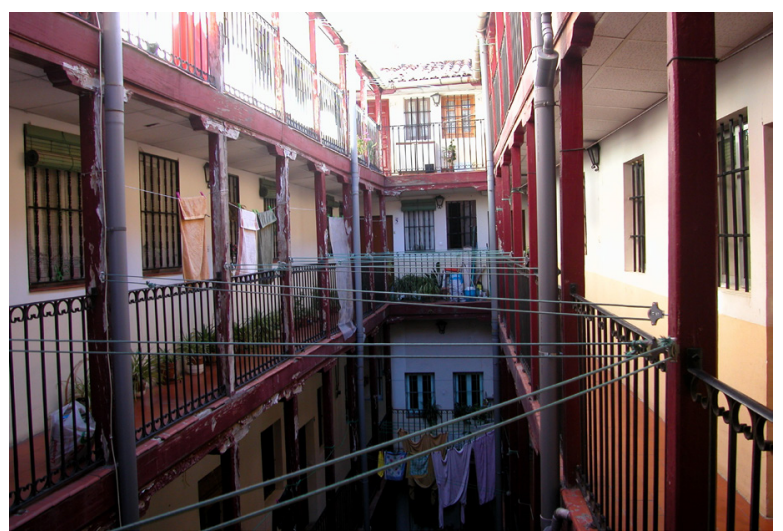

De izquierda a derecha

Figura1. Fotografía aérea del barrio de Lavapiés en el Centro de Madrid. (2006).

Foto. Archivo personal José Hayakawa.

Figura2. Tipo residencial multifamiliar "Corrala" en Lavapiés. (2005).

Foto. Archivo personal Miguel Angel Delgado.

rrala sigue facilitando el aprovechamiento de la parcela y se aprecian varios tipos en función del patio resultante:

\footnotetext{
Cuando hay suficiente anchura se construye una corrala de 3 lados más el cuerpo de fachada, con un patio central. En este caso, aunque las viviendas interiores tengan escasas dimensiones, suelen tener buena ventilación. En otros casos, se construye la corrala de dos lados (ocupando uno de los lados y el fondo de la parcela quedando el patio al lado de la otra medianería) y el cuerpo de fachada. Las viviendas interiores son insalubres por no tener el patio entre medianerías las dimensiones adecuadas. Finalmente, si la parcela es sumamente estrecha sólo es posible la corrala de un lado, siendo en este caso el cuerpo de fachada, salvo las viviendas exteriores (en general 1 por planta). En general disponen de un retrete común y una fuente en el patio (Ruiz, 2006, p. 2).
}

Otros tipos de organización observados muestran que los edificios de mayor calidad se resuelven con un único patio central. Las viviendas más amplias ocupan las crujías de fachada siendo las interiores de tamaño más reducido. En las edificaciones de inferior calidad, la estructura se organiza con una sucesión de patios muy angostos. Normalmente, contaban con dos núcleos de escaleras: uno para el cuerpo edificado exterior y otro para el interior.

Hacia comienzos del siglo XX se produce una decadencia económica y social del barrio de Lavapiés con el desplazamiento de la actividad industrial hacia otras zonas de Madrid y la llegada de una población de escasos recursos económicos. Ello condujo a un 
cierto hacinamiento y degradación en los espacios ocupados como las viviendas en buhardillas y pequeñas piezas al interior de las corralas, sin ventilación natural ni retrete propio ni, en algunos casos, dotación de agua ni electricidad. Con esas condiciones se llegó a mediados del siglo XX con una población envejecida porque los jóvenes se trasladaban a vivir al extrarradio (Figura 4). Las viviendas fueron ocupadas por una inmigración nacional con escasos recursos económicos que siguió hacinándose en aquellas viviendas que incumplían ya con las exigencias contemporáneas de superficie, higiene y salubridad. Así, no hubo una actividad de mejora relevante en los edificios y se continuó con un proceso de deterioro paulatino hasta finales del siglo XX.

El siglo XXI llegó acompañado de un incremento exponencial de la población, en gran parte procedente de la inmigración internacional, en muchos casos sin regularización. (Figura 5) Las precarias situaciones de esta población y su hacinamiento incrementaron el proceso de deterioro, con mayor hacinamiento y más abandono en el cuidado y mantenimiento de los edificios y de las vías públicas. (Figura 6)

Algunos de los problemas más relevantes en esta situación serían los siguientes:

Situación económica, social y patrimonial de evidente deterioro.

Deficiente estado de las infraestructuras básicas, falta de espacios de estar y de zonas verdes.

Carencias y déficit de equipamientos urbanos.

Antigüedad generalizada y mal estado de conservación de las edificaciones, con diversas lesiones de muy complejo tratamiento. Porcentaje elevado de infraviviendas.

Alta marginalidad social.

Transformación del comercio minorista tradicional en comercio mayorista de importación. (Figura 7)

\subsection{Análisis del perfil urbanístico y socio-económico del Lavapiés}

Para diseñar una intervención que solventara la degradación de Lavapiés, se diagnosticaron las carencias y posibilidades urbanísticas y socio-económicas. Se optó por definir un ámbito de actuación, el "Sector I", delimitado por las calles de Embajadores, Duque de Alba, Ave María, Plaza de Lavapiés y calle de Valencia, la Ronda de Valencia hasta la Glorieta de
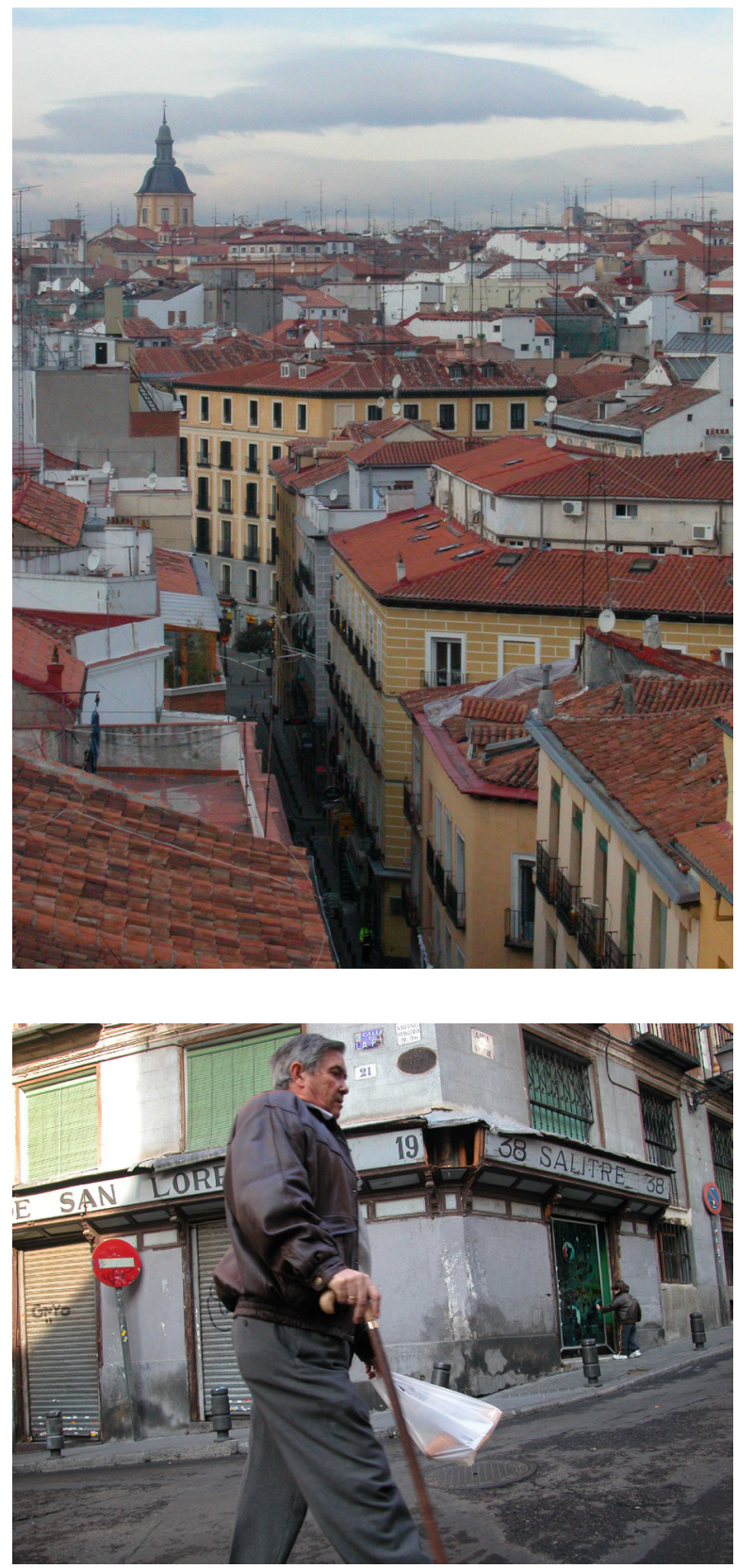

De arriba a abajo

Figura 3. Perfil urbano del barrio de Lavapiés. (2005). Foto. Archivo personal Miguel Angel Delgado.

Figura 4. Vecinos ancianos del barrio de Lavapiés. (2005). Foto. Archivo personal Miguel Angel Delgado. 

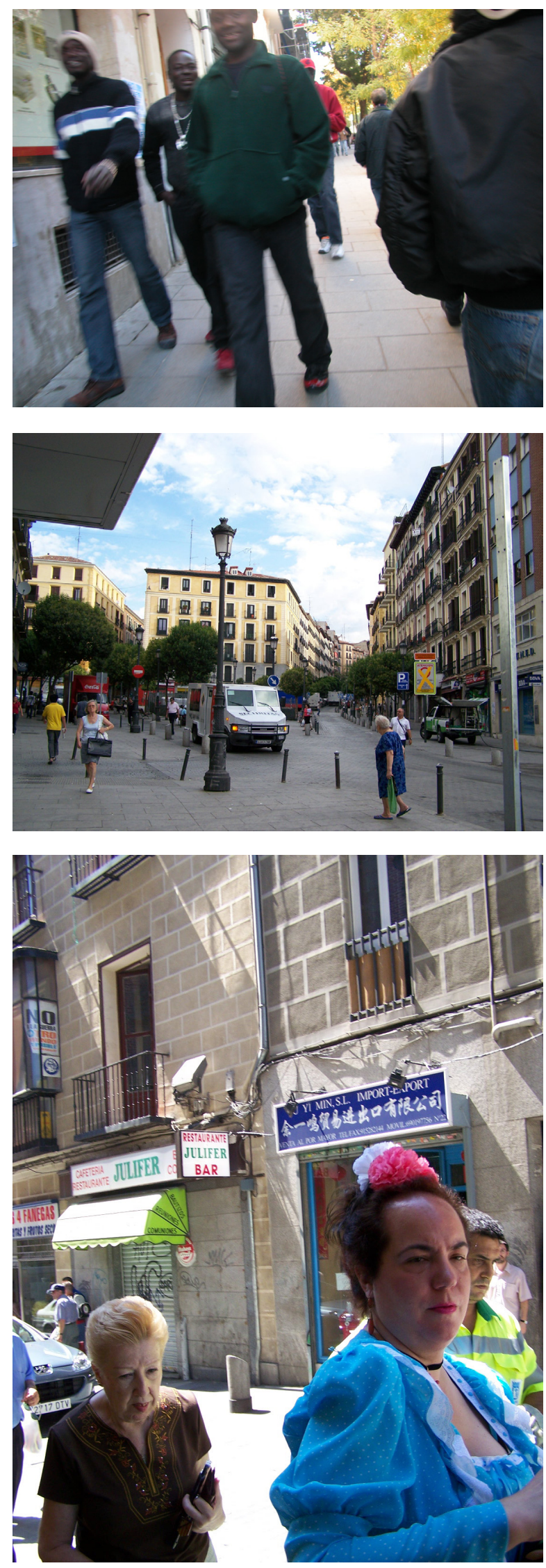

Embajadores, Ronda de Toledo, subiendo por la calle de Las Américas hasta la calle del Casino.

Del documento Áreas de Rehabilitación Preferente en el Centro Histórico y barrios periféricos de Madrid (1994-1999), (Empresa Municipal de la Vivienda. Madrid. 1999) es posible destacar los siguientes datos estratégicos:

Superficie Sector I: 34.5 hectáreas. (29.6 Ha. superficie edificada).

66 manzanas (46 completas y 20 incompletas o de borde; 766 parcelas, de las cuales 10 están libres de edificación).

756 edificios (713 residenciales, 43 dotacionales o terciarios; $28.31 \%$ en buen estado; $71.69 \%$ en regular o mal estado).

11,878 viviendas (667 vacías; 129 a otros usos, representando un $6.62 \%$ de usos no residenciales).

157 edificios con infravivienda (superficie, condiciones higiénico-sanitarias, instalaciones), es decir el $20.77 \%$ de los edificios, con 2,431 infraviviendas, que representan el $20.47 \%$ ).

$60 \%$ de las construcciones supera los 100 años de antigüedad.

Más del $50 \%$ de las viviendas es inferior a los $50 \mathrm{~m}^{2}$.

El $20 \%$ de las viviendas no posee ducha o baño y sin calefacción (Hayakawa, 2006, pp. 3-4).

Los datos esenciales que aporta el perfil socio-económico (2006) son:

"Cambio reciente: inmigrantes de Magreb y África Sub-Sahariana, de Europa Oriental, Asia y Sudamérica (27\% de los escolares matriculados son hijos de inmigrantes).

De arriba a abajo

Figura 5. Nueva población inmigrante en el barrio de Lavapiés. (2005).

Foto. Archivo personal Miguel Angel Delgado.

Figura 6. “Crisol de culturas” en la Plaza de Lavapiés y dinámica de la ciudad hoy. (2006).

Foto. Archivo personal José Hayakawa.

Figura 7. "Lavapiés castizo" en festividades barriales tradicionales. (2006).

Foto. Archivo personal José Hayakawa. 
Distribución por edades: pirámide invertida (25\% es mayor a 65 años, $15 \%$ es menor a 14 años y el $41.9 \%$ está entre los 30 y 64 años).

Sobre el género, el $53.5 \%$ es de sexo femenino y el 46.5 $\%$ son hombres.

Tamaño familiar de 2.1, habitual en el Centro Histórico de Madrid.

La Tasa de actividad comprende un 50 \% de población activa (micro comerciantes, hostelería, administrativos). Magnitudes similares poseen sectores como industria, construcción, directivos y profesionales liberales. La PEA es de 81.3 \% de la población, relacionada al $18.7 \%$ de re-empleados y al $20 \%$ de jubilados.

Nivel de instrucción: "Barrio antiguo y popular" (10 $\%$ son titulados medios y superiores; $18.4 \%$ son analfabetos).

Régimen de Tenencia: Tradicionalmente: alquiler; últimos años: acceso a la propiedad. Propiedad horizontal: $65 \%$.

Nivel de ingresos: Elevado porcentaje de familias no superan en 2 el Salario Mínimo Interprofesional, Mas del $60 \%$ no superan en 3.5 veces el Salario Mínimo Interprofesional (Barañano, Margarita y otros, 2006).

\subsection{Declaración de Área de Rehabilitación Preferen- te (ARP)}

Con la declaración del 12 de mayo de 1997, por Orden de la Consejería de Obras Públicas, Urbanismo y Transporte de la Comunidad de Madrid, del Área de Rehabilitación Preferente (ARP) del Sector I de Lavapiés se articularon esfuerzos por parte de los tres niveles de Administración Pública: estatal, autonómica y local, apoyadas en una fuerte y constante demanda vecinal y con la cobertura de un planeamiento específico de la zona (Área de Planeamiento Específico 00.01 "Centro Histórico"). La instrumentación jurídica para optimizar la inversión en esta área se plasmó a través de la ratificación de sendos convenios suscritos entre la Comunidad de Madrid y el Ayuntamiento de Madrid el 16 de julio de 1997 y entre el Ministerio de Fomento y la Comunidad de Madrid de fecha 12 de diciembre de 1997. El objetivo de los mismos fue "[...]coordinar de forma conjunta e integrada el fomento, programación y ejecución de la política de rehabilitación, tanto de las acciones dirigidas a la recuperación estructural y/o funcional de los edificios, la adecuación de habitabilidad de las viviendas, la mejora medioambiental, así como del equipamiento comunitario primario, adaptándose a la normativa técnica específica y a las normas urbanísticas" (Ruiz, 2006, p.3).

La lógica de intervención en el Área de Rehabilitación Preferente es la siguiente:

Dentro de cada área existe una Actuación Publica consistente en la renovación de las instalaciones urbanas, la urbanización y exornación de las calles, y, mediante los Programas de Adecuación Arquitectónica, la recuperación de las fachadas de los edificios de viviendas, quedando las obras interiores de los inmuebles de las viviendas a cargo de los usuarios, para lo cual los administradores subvencionan el coste de las mismas hasta un 50\% de su valor. La intervención privada de promoción directa se realiza a través de los propietarios de los edificios o comunidad de Propietarios, según el régimen de tenencia. Las actuaciones van encaminadas a la rehabilitación constructiva y funcional de los inmuebles en sus zonas comunes, fachadas y locales comerciales, así como en la mejora de las condiciones higiénicas y de habitabilidad en los interiores de las viviendas (Empresa Municipal de la Vivienda, 2005, p.11).

El denominado Sector I del Lavapiés abarca el área detallada en el punto anterior. Como rezaba la misma memoria institucional, la recuperación del Barrio de Lavapiés

[...]como un barrio diverso y multifuncional es un ambicioso proyecto económico y social, en el cual, la 'calidad de vida, salud y bienestar, representa uno de los objetivos prioritarios. Pero no existe una verdadera 'calidad de vida' si no se incide directamente en la mejora del Medio Ambiente Urbano ya que la calidad ambiental, representa un factor fundamental del bienestar (Ruiz, 2005, p.2).

Como primera actuación se realizó un estudio diagnóstico pormenorizado manzana por manzana y edificio por edificio, el cual refleja en unas fichas el tipo edificatorio, la situación estructural, la organización social, el régimen de la propiedad, la postura poblacional ante la rehabilitación, entre otros. (Figura 8)

Se contempló una inversión total de 54880 millones de euros, de los cuales el aporte financiero del conjunto de las Administraciones Públicas fue del orden de los 39.5 millones, los cuales fueron distribuidos de la siguiente manera:

- Rehabilitación de viviendas: 25470 millones de euros (64\% de la inversión pública). Se calculaba una teórica intervención en 4,000 de las 11,878 viviendas.

Renovación de infraestructuras: 14040 millones de euros (36 \% de la inversión pública). 
Figura 8. Fachada de un multifamiliar degradado en calle “Huerta del Bayo, 8". (2005) Foto. Archivo personal Miguel Angel Delgado.

A su vez, los actores privados invirtieron $15370 \mathrm{mi}-$ llones de euros.

Entre otras inversiones fuera del convenio, se contó con las Aportaciones del Ayuntamiento de Madrid (para equipamientos y el Programa Social) y el Fondo de Cohesión de Mejora del Medio Ambiente Urbano Sector I de Lavapiés (otorgado por la Comisión de la Comunidad Económica Europea con fecha 26 de julio de 1996 y promovido por el Excelentísimo Ayuntamiento de Madrid para realizar las primeras obras de infraestructuras). De esta manera, se puso en acción un sistema de actuación que incidía en la clasificación como Área de Rehabilitación Preferente. La declaración de estas áreas tiene como objetivo "[...]una mejora de la calidad de vida, la recuperación de carácter residencial del centro histórico y barrios periféricos degradados, la regeneración del tejido social, la mejora de las viviendas y edificios, la creación de nuevos servicios, dotaciones, espacios públicos, participación ciudadana" (Ruiz, 2005, p.4).

Tras un largo y profundo estudio de la variedad de problemas y de los posibles modelos de gestión, la solución elegida fue:

[...]establecer una Entidad Gestora que aunase los esfuerzos de los distintos departamentos o direcciones de la Comunidad de Madrid y del Ayuntamiento, creándose por tanto la 'Entidad Gestora para la Promoción, Ejecución y Rehabilitación del Sector I de Lavapiés’ el 10 de diciembre, inscribiéndose posteriormente como Entidad Urbanística Gestora de Rehabilitación. Dicha Entidad goza de plena personalidad jurídica suficiente para la gestión, canalización de ayudas y ejecución del Convenio. La coordinación general del programa corresponde a la Dirección General de Arquitectura y Vivienda de la Comunidad de Madrid,

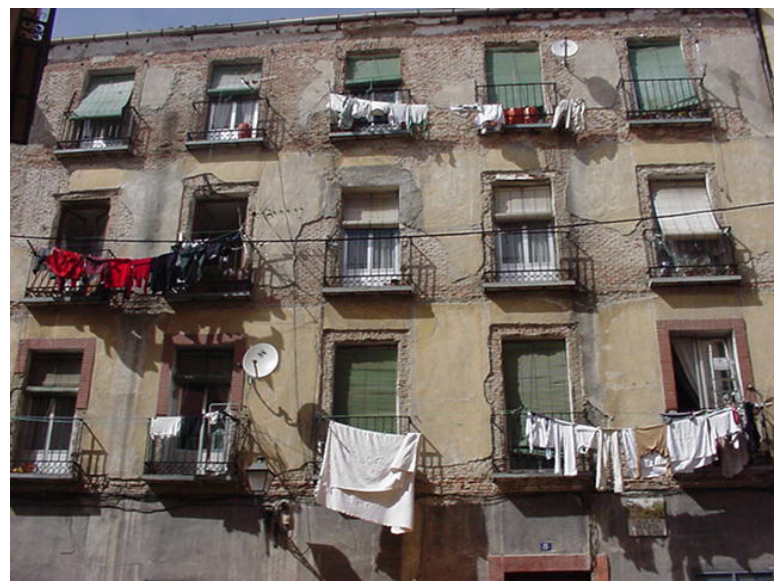

con las competencias que los estatutos establecen (Ruiz, 2006, p. 4).

La actuación sobre las temáticas específicas de la vivienda correspondió a la Empresa Municipal de la Vivienda y Suelo (EMVS). Por otro lado, la actuación sobre urbanización e infraestructuras correspondió a la Gerencia Municipal de Urbanismo.

En junio de 1998, se procedió a la apertura de la Oficina de la Entidad Gestora para la Promoción, Ejecución y Rehabilitación del Sector I de Lavapiés. Se empezó a realizar la tramitación y gestión de los expedientes de ayudas a la rehabilitación privada, con subvención de las obras para la adecuación estructural y constructiva de los edificios así como la adecuación de la habitabilidad de las viviendas. Entonces, las comunidades de propietarios, los propietarios únicos de los edificios destinados al arrendamiento o los titulares de viviendas debían comenzar a tramitar sus respectivos expedientes ante la Entidad Gestora. Dichas promociones, por ser privadas, gozaban de plena libertad para contratar con las empresas que estimasen más convenientes a sus intereses y posibilidades, así como también para la elección de los técnicos de los proyectos y de la dirección facultativa. (Figura 9)

En síntesis, en el Área de Rehabilitación Preferente del Sector I de Lavapiés, como en todas las restantes áreas se conjugaron tres tipos de intervención según Ruiz 2006:

La pública directa que trabaja en las infraestructuras, dotaciones de servicios así como en el equipamiento comunitario primario y en operaciones de erradicación de infravivienda. 
- La pública, previo acuerdo con los titulares de los edificios, que trabaja sobre las fachadas y elementos protegidos, mediante concurso de obras y adjudicación del proyecto por el órgano gestor; es decir, lo que llamamos Programas de Adecuación Arquitectónica. Los beneficiarios tienen como requisito que los promotores de las obras deben ejecutar los interiores con ayudas económicas a fondo perdido, siempre y cuando el edificio lo precise.

- La estrictamente privada. Obras acordadas y ejecutadas por particulares para las que recibirán subvenciones a fondo perdido de las Administraciones

\section{Intervención pública en infraestructuras}

Se intervino preferentemente en la renovación de las redes de alumbrado, abastecimiento de agua y saneamiento, así como en la mejora de las vías públicas con ensanchamiento de veredas, renovación de pavimentos, eliminación de barreras arquitectónicas, plantación de arbolado y mejora del mobiliario urbano. Así mismo, se invirtió en la mejora de las dotaciones del ámbito, del equipamiento comunitario con la actuación de la Administración en varios edificios para soporte de los mismos. Entre las actuaciones realizadas destacan las siguientes:

- Recuperación del Parque Casino de la Reina para los vecinos del barrio. Implicó la rehabilitación del edificio existente para nuevo uso como Centro Comunitario, entendido como lugar de confluencia de las instituciones locales, de la iniciativa social y en general de los vecinos. También destaca la implementación de un Centro de día para ancianos, de una guardería infantil, de un estacionamiento subterráneo para residentes y la instalación de pistas deportivas multiusos.

Ordenamiento y cambio de pavimentación y mobiliario de la Plaza de Lavapiés y de la Plaza de la Corrala.

- Urbanización de la Plaza de Agustín Lara incluyendo la construcción de un aparcamiento subterráneo de 400 plazas para residentes y la nueva distribución de la plaza.

- Rehabilitación del edificio de las Escuelas Pías, antiguo colegio que se encontraba abandonado y en ruinas, para convertirlo en Biblioteca y Aulario de la Universidad Nacional de Educación a Distancia (UNED).

- Rehabilitación del Mercado de San Fernando, con el acondicionamiento de los puestos en planta baja y la ejecución de las obras para el nuevo Centro de Salud en su planta superior.

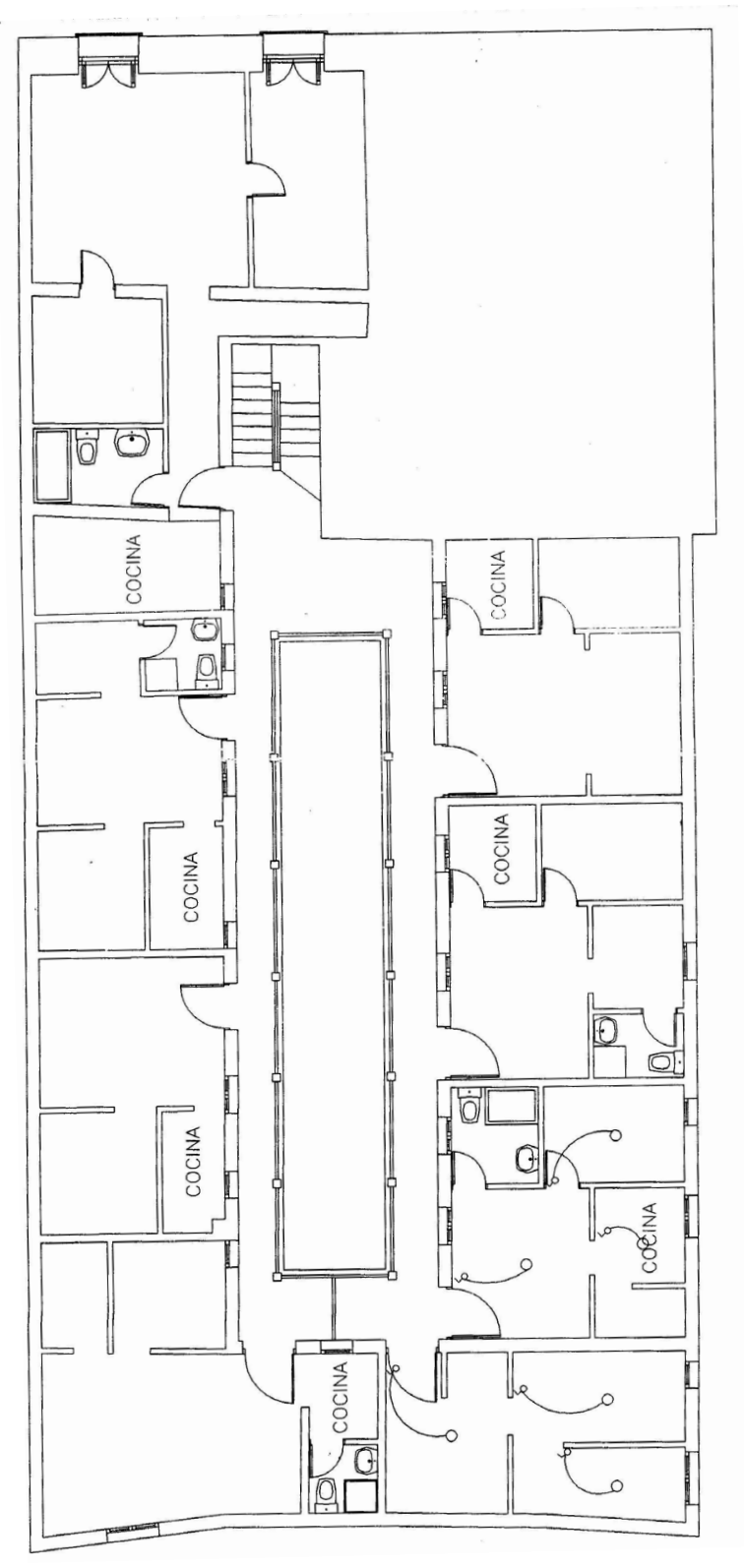

Figura 9. Planta de un multifamiliar degradado en calle "Buenavista, 12". (2005).

Fuente. Archivo planimétrico de la 'Entidad Gestora para la Promoción, Ejecución y Rehabilitación del Sector I de Lavapiés 

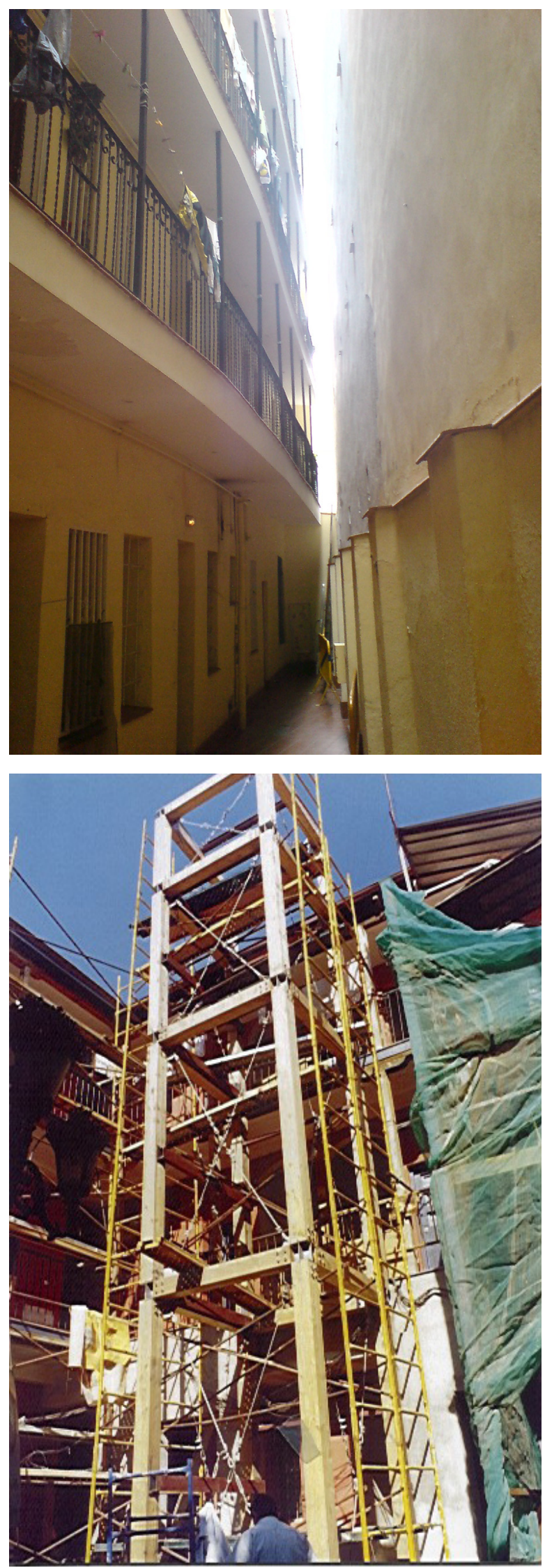

Demolición de la antigua Sala Olimpia de teatro y la construcción del nuevo edificio del Teatro Valle Inclán para el Centro Dramático Nacional.

Por último, las actuaciones públicas de rehabilitación de edificios residenciales por parte de la EMVS se desarrollaron en el marco del programa de adquisición de edificios con un avanzado estado de deterioro para, tras su rehabilitación, destinarlos a realojar las operaciones de erradicación de infravivienda. Entre otros destacan los casos de los edificios situados en: calle del Amparo 57; Amparo 62; Amparo 17; Amparo 34; Lavapiés 38; Lavapiés 13; Casino 6; Encomienda 8; Olmo 21; Tribulete 19; San Carlos 17; Amparo 19; Olmo 8; Sombrerete 14, entre otros. (Figura 10)

Otra operación complementaria a la referida fue la compra de solares, como el de la calle de Embajadores 57 en donde se realizaron obras de nueva planta. En esta misma línea de acción, la Comunidad de Madrid adquirió los inmuebles de las calles de Valencia 8 y 10; Valencia 17; Calvario 11; Cabeza 20 y Cabeza 36.

\section{Intervención pública y privada}

Para mostrar la conveniencia de la rehabilitación en el barrio, se acordó que la Administración abordara una temprana intervención en elementos representativos del ámbito, eligiendo las fachadas de la plaza de Lavapiés y algunas corralas destacadas. Con tal fin, se establecieron dos Programas de Adecuación Arquitectónica en los que la Administración asumía la gestión y coste de las obras aun siendo de propiedad privada. Se ceñían a la zona del edificio propia de dichos elementos, condicionando esta intervención sin coste para los propietarios para que éstos intervinieran en el resto del edificio, ya con las ayudas generales.

\section{De arriba a abajo}

Figura 10. Interior con deficiente iluminación y ventilación natural de multifamiliar. Calle “Amparo, 35”. (2005). Foto. Archivo personal Miguel Angel Delgado.

Figura 11. Ascensor en obras de rehabilitación en un multifamiliar degradado en calle "Tribulete, 25". (2005).

Fuente. Archivo fotográfico de la 'Entidad Gestora para la Promoción, Ejecución y Rehabilitación del Sector I de Lavapiés 
Dentro del Programa de Adecuación de Fachadas en la Plaza de Lavapiés, se trató de intervenir en

[...]las fachadas de los 9 edificios que han firmado el correspondiente Convenio en el que se compromete por un lado la Entidad Gestora a ejecutar las obras recogidas en el Proyecto de Ejecución, que corren en su totalidad a cargo de la misma y por otro lado las Comunidades de Propietarios a realizar las obras obligatorias que figuran en el correspondiente Informe Técnico realizado por la Entidad Gestora, siempre contando con las ayudas establecidas para tal fin (Ruiz, 2006, p. 7).

Dentro del Programa de Itinerario de Corralas, se seleccionaron dos edificios: uno en calle Tribulete 25 y otro en calle Cabestreros 9. (Figura 11)

En el caso de la rehabilitación de las fachadas de los edificios, la Empresa Municipal de la Vivienda exigió como requisito previo a la actuación pública: “[...] que los particulares lleguen a los acuerdos necesarios con el Ente Gestor para que la actuación sea integral, mediante la firma de convenios con vecinos y comerciantes para rehabilitar con subvenciones el interior del edifico en su totalidad" (Empresa Municipal de la Vivienda, 2006, p.10). Caso contrario se hubiese tratado de una operación de "maquillaje urbano" que simplemente ocultaría la realidad social y/o arquitectónica del edificio. En el caso de la adecuación de corralas, las obras consistieron en la adecuación de los espacios interiores: fachadas de los patios de la corrala y elementos comunes que sirven como zaguanes, escaleras y corredores, la eliminación de retretes comunitarios y la instalación de ascensores.

\section{Intervención privada}

Las restantes intervenciones en los edificios residenciales privados fueron promovidas por iniciativa privada de sus propietarios o inquilinos, contando con la subvención económica a fondo perdido de las ayudas generales de la Entidad Gestora de Lavapiés.

Tuvieron como objeto la intervención en los edificios o en las viviendas. En los edificios, las ayudas subvencionaban las obras precisas para alcanzar las debidas condiciones de adecuación estructural y funcional con el objetivo general de mejorar la seguridad, estabilidad, salubridad, habitabilidad, accesibilidad, confortabilidad y ornato de los edificios. En las viviendas, tenían por finalidad alcanzar las debidas condiciones de adecuación de habitabilidad de aquellos edificios que disponían de adecuación estructural y funcional.
En el primer caso, las obras en los elementos comunes se acometían por iniciativa privada de los propietarios de los edificios; es decir, las comunidades de propietarios en el caso de los edificios de propiedad horizontal y del titular en el caso de los de propiedad única. En el segundo caso de mejora de habitabilidad de las viviendas, la actuación podía realizarla el propietario o el arrendatario de la vivienda.

El proceso se iniciaba con la solicitud de ayudas a la oficina de la Entidad Gestora que, a partir de esta acción, realizaba una visita de inspección al edificio para elaborar el respectivo informe técnico en el que se indicaban los problemas detectados y la obligación de solventarlos con las obras para poder acogerse a la subvención. Así mismo, habrían de cumplirse unos requisitos establecidos:

- Al final de las actuaciones el edificio debe tener uso residencial como mínimo en el $60 \%$ del total de su superficie útil.

- Las obras no deben estar comenzadas antes de formalizar la solicitud de ayudas salvo que exista una Orden de Ejecución.

- La antigüedad del edificio debe ser igual o mayor de 15 años (Ruiz, 2006, pp. 7-8).

El informe técnico se remitía al solicitante para que, con las indicaciones del mismo, contratara la realización del Proyecto de Ejecución, el cual debía contemplar al menos todas las obras para subsanar los daños señalados en el informe.

Para continuar la tramitación, el solicitante tenía que aportar una documentación general, propia de la obra a ejecutar (proyecto técnico, licencia de obras, presupuesto de la obra contratada, etc.) y una documentación referente al peticionario de la ayuda (documento de identificación, título de propiedad, declaración fiscal de ingresos, etc.) que en el caso de comunidades de propietarios sería la correspondiente a cada uno de los integrantes de las mismas que la solicitaran

Con toda la documentación exigida, se procedía a la concesión o calificación provisional de las ayudas económicas en la que se determinaba individualmente tanto lo que debía pagar cada vecino como lo que recibiría de subvención. La modalidad de financiamiento contemplaba que al inicio de las obras se solventaba el $50 \%$ de la subvención y el 50\% restante era desembolsado cuando se comprobaba la finalización de las obras y se emitía la correspondiente Cali- 


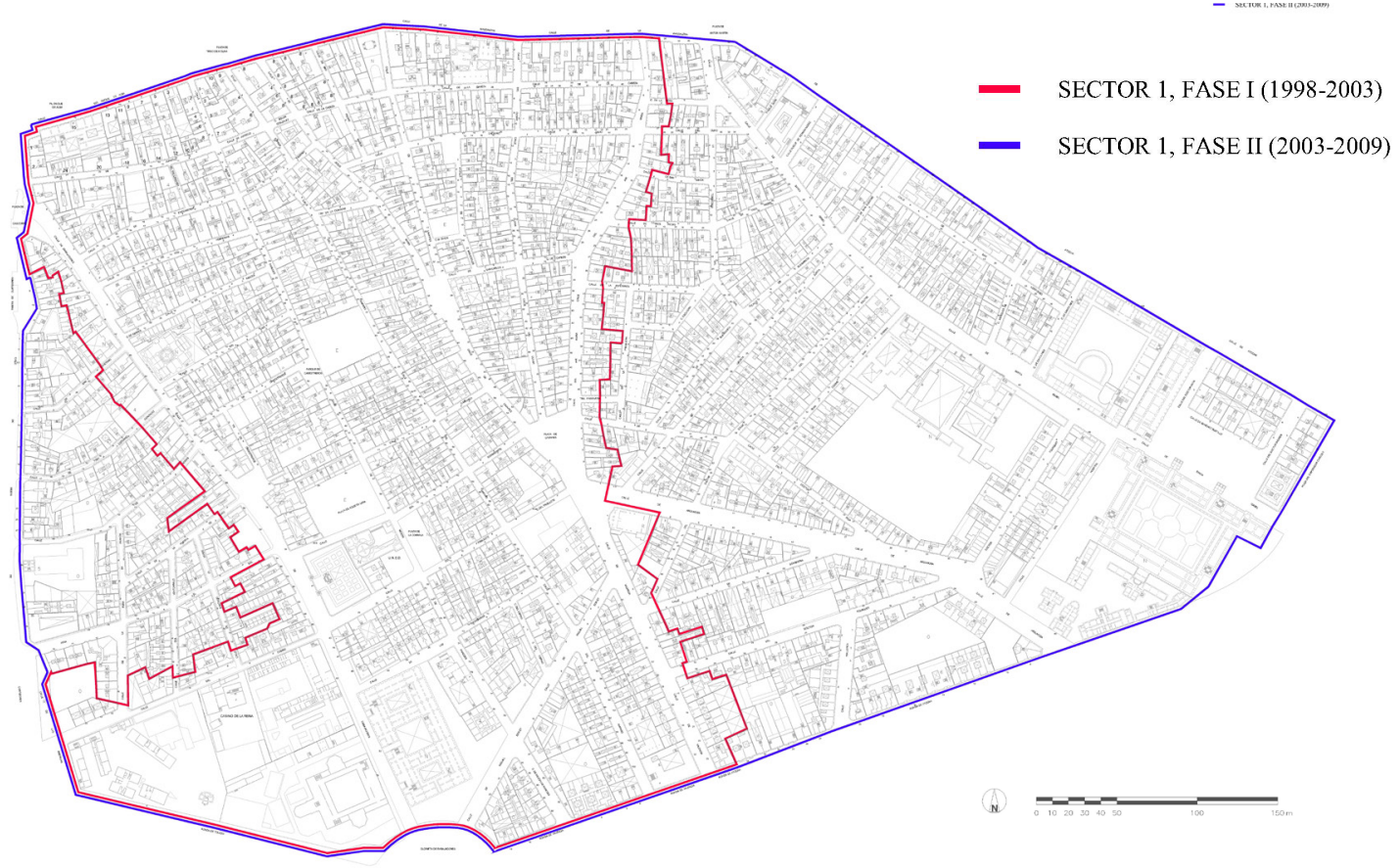

Figura 12. Plano del Área de Rehabilitación Integrada (ARI) de Lavapiés, Sector I - Fase I y II. (2007).

Fuente. Archivo planimétrico de la 'Entidad Gestora para la Promoción, Ejecución y Rehabilitación del Sector I de Lavapiés

ficación Definitiva. En este momento, se comprobaban los costes reales habidos, ajustando a la realidad el valor presupuestado que sirvió de base para la calificación provisional.

Las ayudas se concedían individualmente a cada beneficiario; su importe en cada caso se calculaba en función de diversos factores tales como los tipos de actuación de rehabilitación a ejecutar, el régimen de uso y ocupación de las viviendas y locales, los ingresos familiares ponderados de la unidad familiar de los beneficiarios y de la fecha de formalización y condiciones de los contratos de arrendamiento.

\section{4 Área de Rehabilitación Integrada (ARI) sector I lavapiés. $2^{a}$ Fase (2003-2006)}

En virtud de resultados obtenidos y tomando en consideración que el proceso de revitalización de este sector de la ciudad era lento -por el escaso poder adquisitivo de los habitantes, el incremento desorbitado en los precios de la construcción y el deterioro constructivo de la mayoría de los inmuebles, que dificultan afrontar la totalidad de las obras precisas en un tiempo tan limitado- las Administraciones Públicas decidieron aprobar una nueva inversión, ampliando el perímetro del área. (Figura 12)

Nuevamente se incluía la renovación integral de infraestructuras adaptándolas a las nuevas tecnologías y servicios y la renovación de materiales constructivos en los pavimentos de las vías urbanas y su mobiliario urbano. Se programó una actuación en 38 calles del ARI I Lavapiés.

La Inversión de las Administraciones Públicas fue del orden de los 40620 millones $€$, los cuales fueron distribuidos principalmente en Rehabilitación de Viviendas (25 470 millones €; $63 \%$ ) y Renovación de Infraestructuras (14040 millones $€ ; 35 \%$ )

Los datos de partida eran los siguientes:

- Superficie total de actuación ARI I Lavapiés: 70.82 hectáreas

- Número de edificios del ARI I Lavapiés: 1,352 
- Número de viviendas del ARI I Lavapiés: 22278

- Número de habitantes del ARI I Lavapiés: 57825

La política de la subvención según Ruiz, 2006 fue definida cuantitativamente de la siguiente manera:

Cuantías de la subvención:

El Ministerio de Vivienda aporta el 40 \% del presupuesto protegible sin que pueda exceder de $4,000 €$ por actuación.

- La Comunidad de Madrid aporta hasta el $20 \%$ del presupuesto protegible sin que pueda exceder de 3,606.07 $€$ por actuación.

- El Ayuntamiento de Madrid complementa estas subvenciones las que podrían llegar hasta el 75\% del presupuesto protegible, con unas cuantías máximas entre $10500 €$ y $21000 €$ por actuación

- Actuaciones en elementos comunes:

- Propietarios residentes. Dependiendo de los ingresos familiares ponderados, la subvención varía desde el 30 al $75 \%$ del presupuesto protegible.

- Las viviendas en alquiler tienen una subvención del 50 $\%$ del presupuesto protegible.

Actuaciones en adecuaciones de habitabilidad de viviendas:

Dependiendo de los ingresos familiares ponderados, la subvención puede variar desde el 30 al $50 \%$ del presupuesto protegible y se incrementa en un $25 \%$ si se incorpora la vivienda al Programa de la Agencia Municipal de Alquiler.

\subsection{La infravivienda en Lavapiés}

En enero de 1999, el Ayuntamiento de la ciudad aprueba la Ordenanza de Conservación, Rehabilitación y Estado Ruinoso de las Edificaciones (OCRE$\mathrm{RE})$. Su objetivo era:

[...]regular para el municipio de Madrid la obligación de los propietarios de terrenos, construcciones y edificios, de conservarlos o rehabilitarlos para mantenerlos en estado de seguridad, salubridad, ornato público y decoro a fin de mantener en todo momento las condiciones requeridas para la habitabilidad o el uso efectivo. Se establecen así los deberes de conservación y rehabilitación, que determinan la realización de los trabajos y obras precisas para tales fines (Delgado, 2008).

Y es el concepto del deber de rehabilitación el que se centra en el problema de la infravivienda. El objeto principal de las obras correspondientes al mismo es la eliminación de la infravivienda, la que se define como aquélla que no cumpla con las condiciones mínimas de vivienda, no alcance sus dimensiones, no sea vivienda exterior o no llegue a la altura precisa. Todo ello, según los parámetros correspondientes fijados por el Plan General de Ordenación Urbana de Madrid (PGOUM).

Según Delgado (2008) las exigencias de vivienda mínima requeridas representan:

[...]la regulación normativa de la inquietud social que llevó a diversos arquitectos, desde los años 30 del siglo XX, a perseguir las condiciones óptimas de capacidad, comodidad, salubridad y aspecto de la vivienda mínima. Y así quedan fijados en el Plan General de Ordenación Urbana de Madrid (PGOUM) del año 1999:

Superficie mínima:

a) $38 \mathrm{~m}^{2}$ útiles

b) $25 \mathrm{~m}^{2}$ útiles, en distribución tipo estudio (único espacio más aseo)

Vivienda exterior:

a) apertura a espacio público

b) apertura a área de ubicación preferente de patios ("patio azul")

c) apertura a patio luz $>2 / 3 \mathrm{H}$ o luz $>1 / 2 \mathrm{H}$

Altura mínima:

a) $250 \mathrm{~cm}(220 \mathrm{~cm})$

b) $150 \mathrm{~cm}$ en bajo cubierta

Higiene:

a)dotación de aseo propio (Delgado, 2008).

La exigencia de un aseo propio en el interior de la vivienda descalificaba como vivienda aceptable a las que funcionaban con un retrete comunitario en el corredor del pasillo del edificio y con el uso de las instalaciones de baños públicos para el aseo. Pero es la exigencia de que todas las viviendas sean exteriores la que planteaba una determinación urbanística problemática al considerar que se cumpliría cuando la vivienda diera a espacios públicos abiertos, a grandes patios de manzana o a patios que cumplían una determinada proporción entre su altura y su anchura, y, también, a los espacios marcados por el PGOUM sobre las manzanas del casco histórico denominados "áreas de ubicación preferente de patios". Popularmente, eran denominados "patios azules" por la grafía que los definía en los planos del Planeamiento. (Figura 13) 


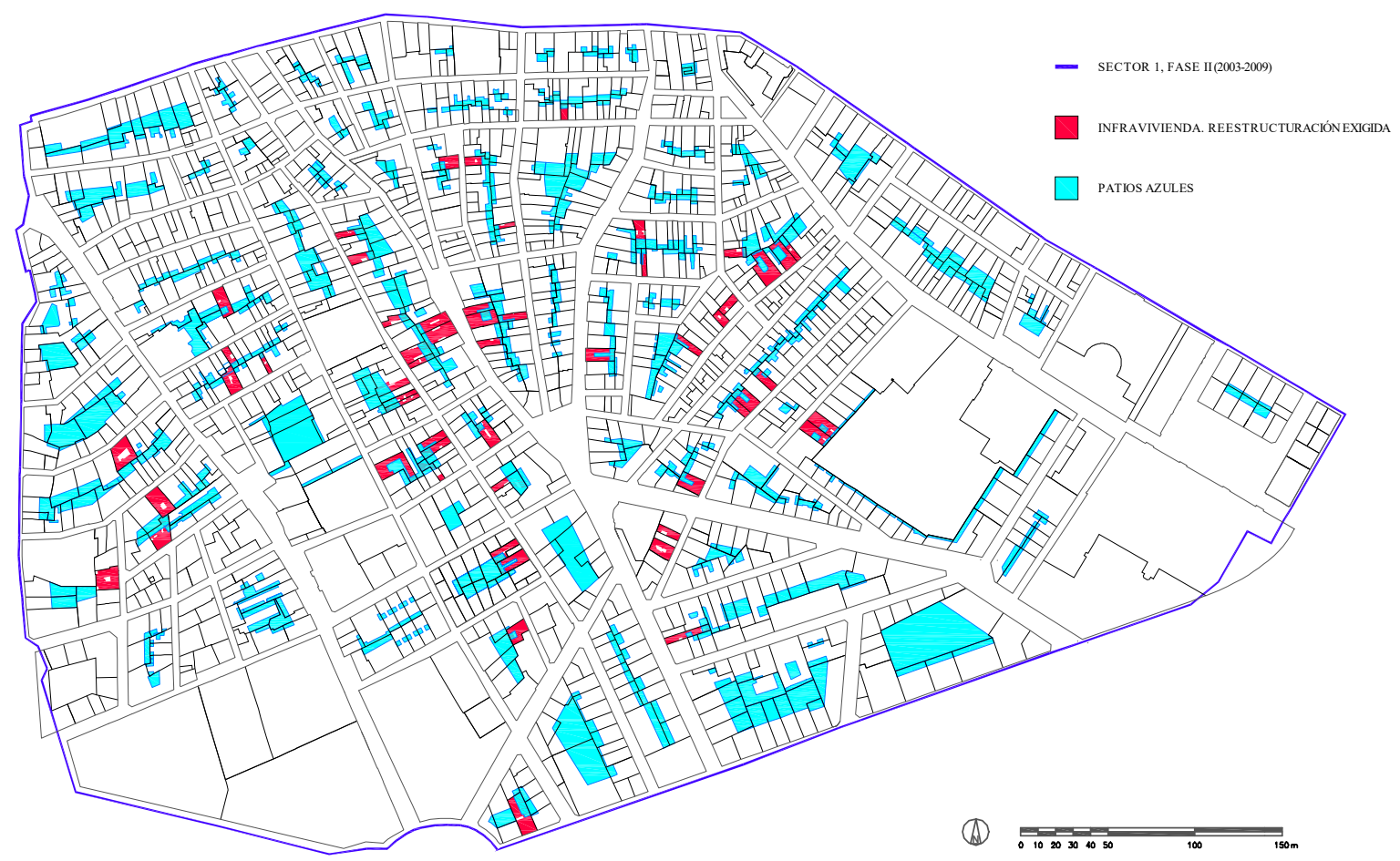

Figura 13. Plano del Área de Rehabilitación Integrada (ARI) de Lavapiés, Edificios con infravivienda generalizada, Patios azules. (2007).

Fuente. Archivo planimétrico de la 'Entidad Gestora para la Promoción, Ejecución y Rehabilitación del Sector I de Lavapiés

Se realizó un estudio de los 770 edificios residenciales comprendidos en esa Fase I del ARI de Lavapiés, con 11,953 viviendas. De acuerdo con las definiciones de la normativa, se comprobó que existía infravivienda en 477 de esos edificios, pues de 9,408 viviendas, 5,512 estaban en esa condición. Por tanto, casi la mitad de las viviendas del ARI de Lavapiés (46,1\%) no cumplía las condiciones mínimas de vivienda y casi las dos terceras partes de los edificios el $(61,9 \%)$ estaban afectadas por la infravivienda.

Una vez comprobado por los técnicos que un edificio que solicita ayudas a la rehabilitación tiene infravivienda generalizada, se pone en marcha el procedimiento de gestión. La concesión de ayudas queda condicionada a la realización de las correspondientes obras de rehabilitación que eliminen las infraviviendas existentes y eso supone la reestructuración del edificio, con la ampliación del patio y la reducción de la superficie construida, así como la disminución del número de viviendas existentes y la modificación (incremento de superficie) de alguna de las restantes (Ruiz, 2006, p.9).
Se establecieron así las Ayudas Especiales dispuestas para las actuaciones destinadas a erradicar la infravivienda (indemnización por erradicación de infravivienda más subvención a las obras) de tal manera que:

[...] los edificios que tenían una gran incidencia de infraviviendas no se acogerían a las ayudas generales para las obras de conservación y reparación, y sólo contarían con las ayudas especiales, que exigían la erradicación de la infravivienda. Las ayudas especiales comprenden tanto indemnizaciones para los propietarios que pierdan superficie de sus viviendas en el necesario proceso de reestructuración, como subvenciones para ejecutar dichas obras (Delgado, 2008).

Así, a los propietarios que abandonen el edificio serían compensados con las ayudas especiales mediante indemnización monetaria o con permuta de superficie residencial por otra en los edificios destinados a realojos. A la vez, se subvencionarían las 
obras de reestructuración para los propietarios que permanecieran en la nueva propiedad.

Frente a la favorable oportunidad de este plan de rehabilitación subvencionado, surge la frustración vecinal, ya que jurídicamente es necesaria la unanimidad de todos los propietarios (100\% de las cuotas de participación al tener que modificar el título constitutivo del edificio) para poder acometer la rehabilitación integral propuesta y fueron múltiples las circunstancias que dificultaban dicha unanimidad.

Vistas las dificultades, la aplicación del concepto de infravivienda, en el marco de la operación de erradicación de la misma en el Sector I de Lavapiés, quedó matizada, por lo que se disminuyeron los requisitos mínimos. Las características inherentes a la intervención pública, política en el ARI I de Lavapiés así lo exigían. Las exigencias de vivienda mínima de la normativa superaban la realidad histórica de numerosas fincas del entramado urbano-histórico y desde el principio de la actuación en el área no se adoptó estrictamente la disposición normativa para valorar la incidencia de la infravivienda en una finca. Por ello:

[...] se definieron unos criterios adaptados al particular ámbito residencial para determinar, en caso extremo, la necesidad de la reestructuración del edificio para la concesión de ayudas a la rehabilitación. Estos criterios para determinar los edificios que, imprescindiblemente, deberían erradicar sus infraviviendas para poder acogerse a las ayudas, valoraban parámetros tales como el porcentaje de viviendas que incumplían las condiciones de habitabilidad, el estado de conservación del edificio, su afección por el área de ubicación preferente de patios, las condiciones de sus patios interiores e influencia de su reestructuración en la regeneración de la manzana (Delgado, 2008).

Con esta información, se determinaba la actuación más conveniente para la intervención en las fincas con infravivienda generalizada que solicitaban ayudas. Se estimaba así la conveniencia de su conservación, con las ayudas generales para las obras necesarias en el edificio o la de acometer su reestructuración, con las ayudas especiales.

\subsection{Balance de la erradicación de infravivienda en Lavapiés}

La erradicación de infravivienda quedó condicionada a la iniciativa privada de los propietarios de los edificios. La actuación pública iría a financiar una parte importante de esta.
Los problemas surgieron más que en la reestructuración física de los edificios en la reestructuración legal de los mismos con la modificación del título constitutivo de la propiedad y la variación de su composición. Se requería para ello la unanimidad de los propietarios, que era difícil de obtener. Es posible identificar los principales problemas que dificultaron la erradicación de la infravivienda por parte de la iniciativa privada:

Falta de interés de algunos propietarios. Muchos de ellos no eran residentes en sus viviendas y valoraban más otras opciones de rentabilidad de sus inmuebles en un momento de gran especulación en el mercado inmobiliario.

Fluctuación de los propietarios de viviendas. La dilación de los procesos propiciaba que se contemplaran cambios de titularidad de muchas viviendas, por lo que se requería la adhesión al proceso de los nuevos propietarios y el inicio de nuevos ajustes para la reestructuración.

Dificultad para el levantamiento anticipado de las cargas registrales vigentes. La situación económica de muchos propietarios hacía inviable la liquidación de hipotecas y embargos existentes sobre sus viviendas.

Urgencia para acometer obras de consolidación. El mal estado de muchas fincas, que contaban incluso con apremiantes órdenes de ejecución para obras de seguridad del edificio dificultaba poder seguir con el proceso más lento y complicado de reestructuración.

- Problemas jurídicos de los propietarios. Existían diversos problemas en la posesión y titularidad de las viviendas con numerosas situaciones en las que los ocupantes de viviendas no se correspondían con los que legalmente figuraban en el título de propiedad o en los datos registrales.

Problemas de ocupación irregular. Muchas infraviviendas estaban ocupadas por inmigrantes en situación irregular. Las habían adquirido en contrato privado de compra-venta o eran alquileres irregulares. Frecuentemente, convivía un elevado número de personas y su situación irregular imposibilitaba el acceso a las ayudas.

Especulación inmobiliaria. Existía en la zona, sobre todo desde el año 2001, una creciente demanda de mercado de venta y alquiler, con precios muy elevados comparados con una valoración objetiva de los inmuebles. Las indemnizaciones previstas quedaban muchas veces por debajo de los precios de ese mercado. 

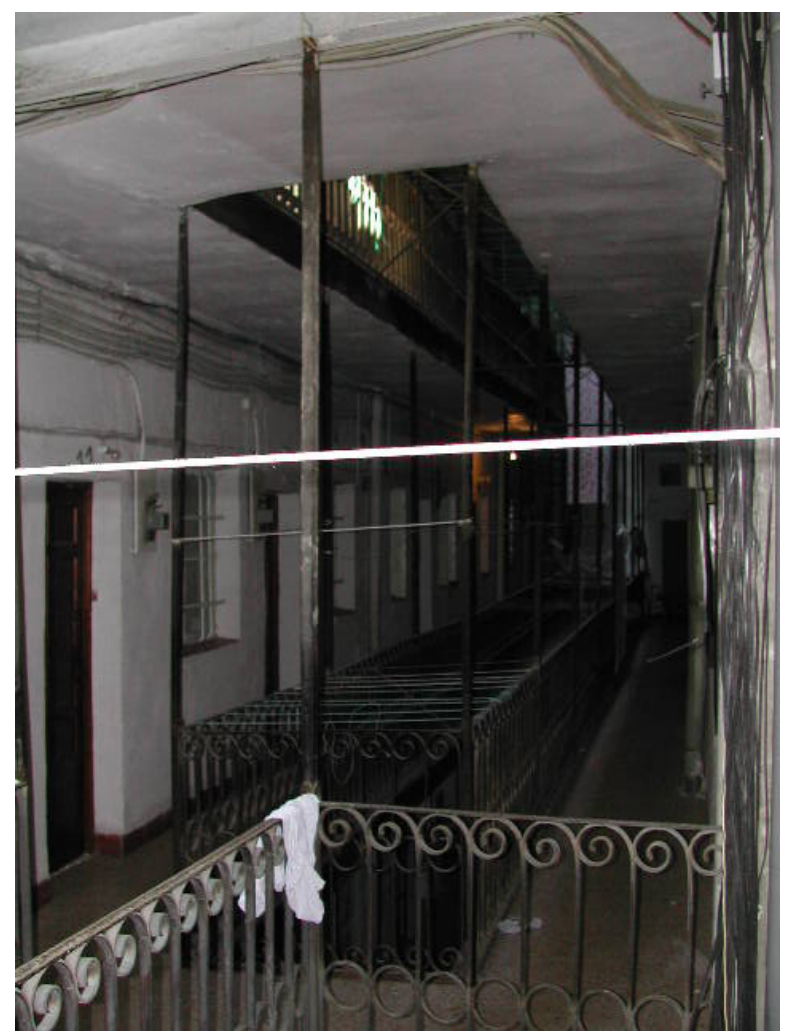

De arriba a abajo, de izquierda a derecha

Figura 14. Interior con deficiente iluminación y ventilación natural en un multifamiliar en calle "Ronda de Valencia, 14". (2005).

Foto. Archivo personal Miguel Ángel Delgado.

Figura 15. Estrechez de circulaciones horizontales en un multifamiliar en calle "Ronda de Valencia, 14". (2005).

Foto. Archivo personal Miguel Ángel Delgado.

Figura 16. Instalaciones eléctricas precarias en un multifamiliar en calle "Ronda de Valencia, 14". (2005).

Foto. Archivo personal Miguel Ángel Delgado.
Bolsas de población envejecida En todos los edificios reside un porcentaje de población de avanzada edad y generalmente de escasos recursos económicos que son reacios a acometer la intervención, por molestias y economía.

Este "abanico" de problemas urbanísticos, jurídicos, sociales y económicos asociados a la "infravivienda generalizada" en Lavapiés impidió que la tramitación de los expedientes no tuviera los resultados positivos esperados. Para promover la erradicación de infravivienda sólo se contó con el incentivo de las medidas económicas, a la espera de que los particulares realizaran de forma voluntaria las obras de rehabilitación integral al sentirse lo suficientemente motivados para acometer la rehabilitación integral del edificio. El cumplimiento del deber de rehabilitación, para la erradicación de la infravivienda en los edificios, exige "[...] una reestructuración de éstos que amplíe la superficie de los espacios abiertos interiores de parcela, ajustándose al área de ubicación preferente de patios. A la vez ha de realizarse una reagrupación de las distintas viviendas para conseguir que todas ellas alcancen la superficie mínima, aparte de la condición de vivienda exterior" (Delgado, 2008). La sencillez del texto de la Ordenanza sobre Conservación, Rehabilitación, y Estado Ruinoso de las Edificaciones (OCRERE) se traducía contundentemente en demolición de zonas de los viejos edificios, con la pérdida de algunas viviendas en cada edificio para abrir patios y aumentar superficie en las resultantes. Esto implica no solo inversión económica sino tiempo y no resultó viable que los propietarios consiguieran con una gestión acelerada la condición de vivienda mínima para sus antiguas edificaciones. (Figura 14).

Finalmente, se propuso una reconsideración de la actuación: se planteó que, por parte de la Gerencia $\mathrm{Mu}$ nicipal de Urbanismo, se valoraran las dificultades de la gestión y se iniciara en algún expediente la aplicación de la "orden de rehabilitación" regulada por la OCRERE. En su artículo 6, se refería al contenido del "deber de rehabilitación y tenía por objetivo la rehabilitación de las instalaciones y la eliminación de la infravivienda”. Igualmente, se planteó inclusive la posibilidad de expropiar dichos inmuebles, al poner en práctica los instrumentos de gestión que en materia de rehabilitación se regulan por la vigente Ley 9/01 del 17 de julio, del Suelo de la Comunidad de Madrid (B. O. C. M. No 177) y que podrían impulsar la erradicación de la infravivienda en las operaciones 
de rehabilitación programadas en la segunda fase del Sector I de Lavapiés. (Figura 15).

Tras ya varios años de existencia del Área de Rehabilitación Integral (ARI) de Lavapiés, incluyendo su ampliación, el resultado resultó deficitario. Es posible concluir con que “...la erradicación de la infravivienda confiando en la iniciativa privada y contando con ayudas públicas no se ha conseguido. La zona ha recibido en este tiempo una gran inversión económica, tanto en las obras de infraestructuras y dotaciones, como en subvenciones para las ayudas generales" (Delgado, 2008). (Figura 16).

\section{Bibliografía}

Ballart, J. (2002). El patrimonio histórico y arqueológico. Valor y uso. Barcelona: Editorial Ariel S.A.

Ballart, J. \& Tresserras, J. (2001). Gestión del patrimonio cultural. Barcelona: Editorial Ariel S.A.

Barañano, M. et al. (2006). Globalización, inmigración transnacional y restructuración de la Región Metropolitana de Madrid. Estudio del barrio de Embajadores de Madrid. Madrid: Fundación de Estudios Sindicales - Ediciones GPS.

Coulomb, R. (2008). Sustentabilidad de la Centralidad urbana e Histórica. Una Reflexión desde el Centro Histórico de la Ciudad de México. Quivera - Revista de estudios urbanos, regionales, territoriales, ambientales y sociales, pp.2-29.

Carrión, F. (Ed). (2000). Desarrollo cultural y gestión en centros históricos. Quito: Facultad Latinoamericana de Ciencias Sociales (FLACSO)-Ecuador - Empresa del Centro Histórico.

Cornejo, J. (1987). Cuadernos de Historia III: Estado y cultura en el Perú republicano. Lima: Editorial Departamento Académico de Ciencias Humanas Universidad de Lima.

Delgado, M. A. (2008). Ser o no ser infravivienda en Madrid. El caso de Lavapiés. Texto inédito no publicado.

Empresa Municipal de la Vivienda. (2005): Obras de urbanización e infraestructuras del barrio de Maravillas. 1 Fase. Madrid: Ayuntamiento de Madrid.

Empresa Municipal de la Vivienda. (2006). 4 proyectos de rehabilitación de la Empresa Municipal de la Vivienda del Ayuntamiento de Madrid. Madrid: Ayuntamiento de Madrid.

García, N. (2007). ¿Qué son los imaginarios y cómo actúan en la ciudad?. Eure - Revista especializada en estudios urbanos y regionales, pp.89-99.
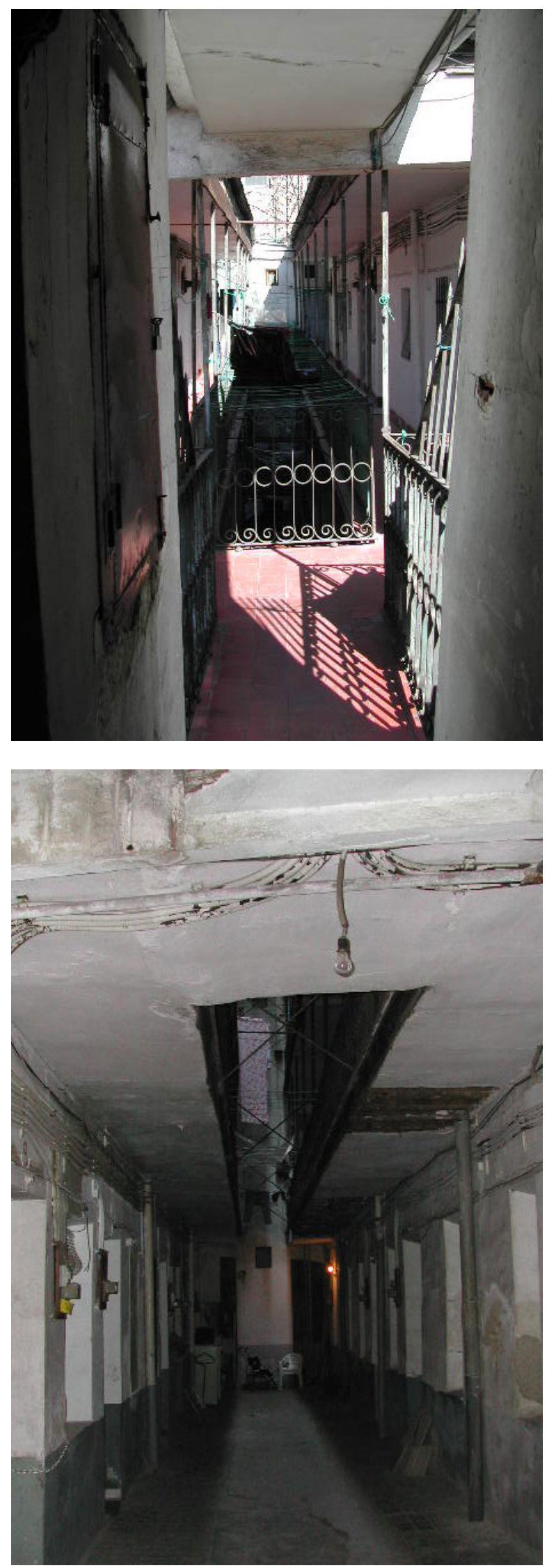
Hayakawa, J. (2010). Gestión del patrimonio cultural y Centros Históricos latinoamericanos. Tendiendo puentes entre el patrimonio y la ciudad. Lima: Universidad Nacional de Ingeniería.

Instituto Nacional de Cultura. (1977). Los Centros Históricos ante el crecimiento de las ciudades contemporáneas. RUNA - Revista del Instituto Nacional de Cultura (INC), pp.2-19.

Lescano, Gr. \& Stolovich, L. (2000). La gestión del patrimonio nacional y cultural en Uruguay. Texto inédito no publicado.

López, J. (2003). Para una filosofía de la ciudad. Ur[b]es Revista de ciudad, urbanismo y paisaje, pp.1-28.

Prats, L. (1997). Antropología y patrimonio. Barcelona: Editorial Ariel S.A.
Rincón, F. (2000). Memorias Cátedra Unesco Gestión integral del patrimonio. En Riobóo, F. (Ed.). (2002). Una forma de entender la problemática patrimonial. Córdoba: Programa de Patrimonio Histórico de la Diputación de Córdoba.

Ruiz, A. (2005). Área de Rehabilitación Integrada. Sector I Lavapiés. Madrid: Entidad Gestora Lavapiés

Ruiz, A. (2006). Intervención en el ARI Sector I Lavapiés. Madrid: Entidad Gestora Lavapiés - Documento inédito.

Riobóo, F. (2002). Una forma de entender la problemática patrimonial. Córdoba España:Programa de Patrimonio Histórico de la Diputación de Córdoba.

Teixeira, P. (1656). Mantua Carpetatorum sive Matritum Urbs Regia. Plano en perspectiva caballera de la ciudad de Madrid en el siglo XVII. 